\title{
Universiteit van Luxemburg als groeipool
}

\author{
CASUS Tim Cassiers
}

\section{In 2003 hield het Groothertogdom Luxemburg haar eigen universiteit boven de doopvont. Welke debatten gingen vooraf aan die beslissing en welke motieven gaven de doorslag bij haar stichting?}

Tot 2003 bestond het hoger onderwijslandschap in het Groothertogdom Luxemburg uit het Centre Universitaire de Luxemburg (CUNLUX) en een aantal hogescholen. Luxemburgse studenten konden in het land wel een academische opleiding starten, maar dienden deze vervolgens af te maken aan buitenlandse universiteiten, voornamelijk in Duitsland, Frankrijk en België.

In de jaren tachtig kwam een serieus debat op gang rond de noodzaak van het aanbieden van voortgezet hoger onderwijs in Luxemburg dat in de jaren negentig in een stroomversnelling geraakte. Heel lang hadden verschillende persoonlijkheden in de Luxemburgse politiek de boot afgehouden. Ze hielden aan dat het land te klein was voor een volwaardige universiteit, dat de jaren van buitenlandse studie een enorme verrijking betekenden voor Luxemburgse studenten, en bovenal dat het land toch al economisch floreerde zonder een bijkomende inzet in het hoger onderwijs. Toch kristalliseerde het debat in 2000 in een witboek dat de oprichting van een universiteit in Luxemburg rechtvaardigde. De voorvechters haalden dus hun slag thuis. Met de wet van 12 augustus 2003 werd officieel de Universiteit van Luxemburg (Uni Lu) gesticht. De universiteit kreeg drie faculteiten: Natuurwetenschappen, Technologie en Communicatiewetenschappen (NTC), Rechtswetenschappen, Wiskunde, Economie en Bedrijfskunde (RWEB), en Letteren en Literatuur, Geesteswetenschappen, Kunst en Onderwijswetenschappen (LGKO).

\section{Jarenlang debat}

Waarom kende dit jarenlange debat zijn beslag? De stichting van de Uni Lu kwam niet uit het niets. In de loop van de jaren tachtig en negentig werd geleidelijk aan de slagkracht en het budget van de Luxemburgse wetenschap verhoogd. Zo zagen niet minder dan veertien onderzoeksen onderwijscentra in die periode het levenslicht. Bovendien werd in 1987 voor het eerst in de Luxemburgse geschiedenis een wetgevend kader geschapen voor de ondersteuning van onderzoek en ontwikkeling Het oogpunt was op dat moment echter hoofdzakelijk procedureel. Deze wet bood bijgevolg geen duidelijke lijn of doelstellingen. Onderzoek was in hoge mate bottom-up gestuurd, bouwend op individueel engagement en idealisme. Dat veranderde in 1999. Met de oprichting van het Fonds Nationale de Recherche en de creatie van een apart departement voor onderzoek binnen het Ministerie van Cultuur, kreeg het Luxemburgse wetenschapsbeleid een aantal duidelijke oriëntaties mee. Enkel de kers op de taart ontbrak nog: de oprichting van de Universiteit van Luxemburg in 2003.

Het valt op dat de klemtoon van het debat langzaam veranderde van hoger onderwijs naar onderzoek. De argumenten betreffende de grootte van het land en de culturele verrijking van een buitenlandse studie, die eerder aansluiten bij de onderwijstaken van een universiteit, raakten daarmee op de achtergrond. Focus kwam steeds meer te liggen op onderzoek en de bijdrage die dit zou kunnen leveren aan de Luxemburgse ontwikkeling. Deze evolutie loopt parallel aan een Europees debat over de kenniseconomie, dat in 2000 uitmondde in de Lissabonstrategie van de EU. Deze had als oogpunt Europa de meest competitieve en dynamische kenniseconomie ter wereld te maken. Binnen deze strategie speelde de zogenaamde 'driehoek van de kennis' - hoger onderwijs, onderzoek en innovatie - een sleutelrol. Elk land werd gevraagd om hier op in te zetten en zo bij te dragen aan het welslagen van de Lissabonstrategie.

\section{Onderwijs bijkomstig?}

Het is inderdaad de symbiose tussen onderwijs, onderzoek en innovatie die als een van de belangrijkste argumenten pro universiteit naar voren werd geschoven. Uit het voorgaande blijkt duidelijk dat onderwijs daarbij niet de doorslag gaf. Toch was dit ook niet volledig bijkomstig in het hele 


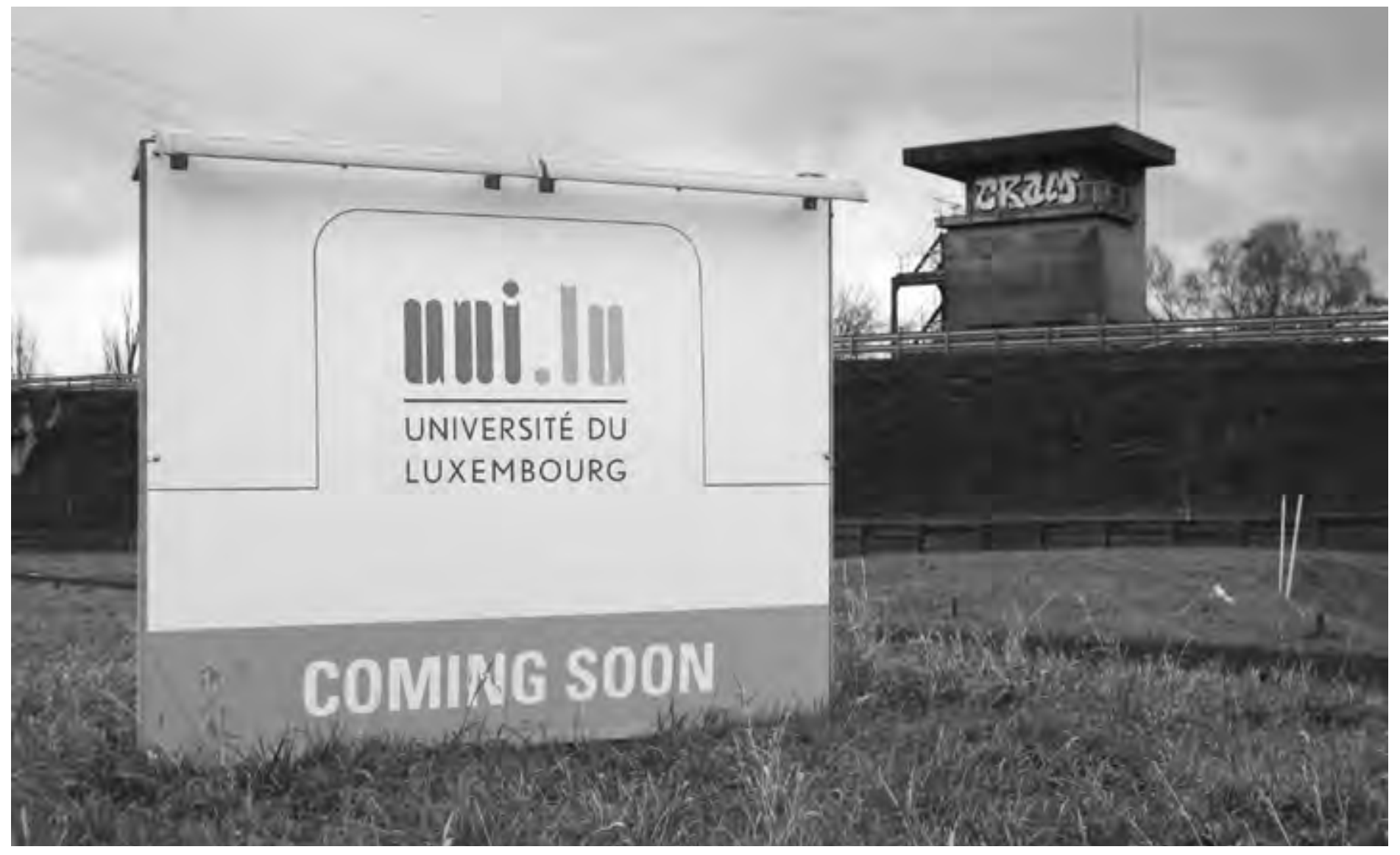

De Uni Lu moet de oude staalsite van Belval nieuw leven inblazen. Foto: Tim Cassiers

verhaal. Luxemburg behoorde immers op het vlak van hoger onderwijs niet bij de Europese top. Volgens de cijfers van het OECD scoorde Luxemburg in het jaar 2000 nog vier percentpunten onder het gemiddelde op het gebied van het aandeel van de bevolking met een hoger of universitair diploma. Veel topfuncties in Luxemburgse bedrijven en instellingen worden bijgevolg ingenomen door buitenlandse hoogopgeleide werknemers. De stichting van een universiteit waarbij Luxemburgse studenten hun opleiding kunnen afmaken in eigen land, zou de stap naar hoger onderwijs dus moeten vergemakkelijken. Bovendien vereist een kenniseconomie constante bijscholing, om up-to-date te zijn met de meest recente kennis, data en modellen. Ook dit lijkt makkelijker als het land over een eigen universiteit beschikt.

Maar Luxemburg zag vooral een opportuniteit om zich via de Uni Lu in te schakelen in internationale kennisnetwerken. Met de Bolognahervorming van het hoger onderwijs zijn universiteiten immers steeds internationaler geworden. Het Groothertogdom zag dat ze met haar meertaligheid, hoge studentenmobiliteit en hoog aandeel aan buitenlandse werknemers op dat vlak heel wat troeven in handen had. Internationale en interdisciplinaire onderzoeksprojecten enerzijds en internationale uitwisselingsprogramma's voor studenten en onderzoekers anderzijds zijn dan ook twee belangrijke steunpilaren van de Uni Lu geworden.

Belangrijker nog dan het onderwijs is daarbij de innovatiekracht die van een universiteit uitgaat, via haar internationale verwevenheid en haar lokale inbedding. Het hele leven rond de universiteit - de onderzoekers en professoren, de studenten, de alumni, en de activiteiten en debatten die ze op gang trekken - wordt gezegd bij te dragen aan een vruchtbare voedingsbodem voor een innovatieve kenniseconomie. Ze creëert een wetenschappelijke cultuur die de sociale, culturele en economische ontwikkeling van het land moet voort stomen.

\section{Investering verdubbeld}

Het argument rond het economisch belang van de Uni Lu werd in politieke zin ondersteund door de Lissabonstrategie van de EU. Gezien Luxemburg op het vlak van onderzoek, innovatie en hoger onderwijs duidelijk achter lag ten opzichte van vele andere EU-lidstaten, zag het land zich genoodzaakt tot een inhaalbeweging. En met het Luxemburgse EU-voorzitterschap in de eerste helft van 2005 in het vooruitzicht -een voorzitterschap dat in hoge mate in het licht zou staan van de evaluatie van de Lissabon doelstellingen - stond bovendien het prestige van het Groothertogdom op het spel.

Maar ook los van de Europese ontwikkelingsstrategieën, vond de idee om in te zetten op kenniseconomie meer en meer ingang. Het argument dat Luxemburg, bekend om zijn gedegen financiële instellingen, het sowieso voor de wind ging, kwam in de jaren 2000 onder druk te staan. Net die vrijwel eenzijdige afhankelijkheid van de bank- en financiënsector bleek de achilleshiel van de Luxemburgse economie. De dotcomzeepbel van begin 2000 en - later - de kredietcrisis van 2007 zetten de broosheid van de financiële sector in de verf. Bovendien knaagde ook de EU aan de wortels van het Luxemburgse groeimodel, wanneer ze met de 'Richtlijn betreffende de belastingheffing op inkomsten uit spaargelden' uit 2003 de (interne) belastingparadijzen in het vizier neemt. 
Deze ontwikkelingen gaven extra gewicht aan de stemmen die hamerden op bijkomende investeringen in onderzoek en ontwikkeling als diversificatiestrategie voor de Luxemburgse economie.

De stichting van de Uni Lu was echter geen eindpunt. Deze werd integendeel een belangrijke bouwsteen van een versterkt beleid inzake innovatie en groei. In het 'plan voor innovatie en volledige tewerkstelling' schoof de Luxemburgse regering onderzoek en ontwikkeling naar voren als belangrijk onderdeel van het economisch ontwikkelingsbeleid. Harde doelstellingen, zoals prestatiecontracten met onderzoeksinstellingen en een afbakening van prioritaire onderzoeksdomeinen, namen de plaats in van softe bewoordingen over 'wetenschappelijke cultuur en uitstraling'. Op minder dan tien jaar tijd werd de financiering voor wetenschappelijk onderzoek meer dan verdubbeld: van 114 miljoen euro in 2006 (of 0,35\% van het BNP) ging het naar 280 miljoen euro in 2013 (of 0,66\% van het BNP).

\section{Luxemburg behoorde op het vlak van hoger onderwijs niet bij de Europese top}

\section{Goede resultaten}

Deze evolutie valt niet los te zien van de door Huo en Stephens beschreven veranderingen in de politieke economie, namelijk een overgang van een meer corporatistische staat naar een sociale investeringsstaat. Door de veranderende economische context en de internationale reguleringen rond overheidssteun, dienden staten investeringen in hun industrieel complex (in Luxemburg meer bepaald in de staalindustrie) af te bouwen. Door zich vervolgens toe te spitsen op sociale investeringen, zochten staten op een andere manier te investeren in de economie. Een klassieke verschijningsvorm hiervan is het inzetten op een meer en beter opgeleide bevolking via het optrekken van de fondsen voor universiteiten en andere opleiding- en onderzoeksinstellingen. Daarnaast is ook het inlijven van tot daarvoor redelijke onafhankelijke instellingen in van bovenaf opgelegde ontwikkelingsdoelstellingen een beproefde strategie. De Luxemburgse staat bedient zich dus ook van deze recepten met de Uni Lu als haar speerpunt. En dat loont. Met meer dan 6000 ingeschreven studenten in 2012 in bachelor, master en doctoraatstrajecten lost de universiteit meer dan de verwachtingen in. Bovendien blijkt dit niet ten koste te gaan van het aantal Luxemburgse studenten dat zich inschrijft aan buitenlandse universiteiten (ruim 10.000). Dat uit zich ook in de algemene scholingsgraad van de bevolking. Deze steeg van $19 \%$ hooggeschoolden in 2001 naar 27\% in 2011, al kan deze fenomenale groeiratio deels verklaard worden door de immigratie van hoogopgeleide buitenlanders. Voor de Luxemburgse nationale bevolking bedroeg het aantal hoogopgeleiden $23 \%$ in 2011.

Ook op onderzoeksvlak kan de Uni Lu goede resultaten voorleggen. Met vijf patenten en twee licenties de afgelopen drie jaar haalt ze haar vooropgestelde doelstellingen. Al is dit maar een zeer beperkte bijdrage aan het totaal aantal patenten en licenties in Luxemburg, waar traditioneel om en bij de $80 \%$ van onderzoek en ontwikkeling binnen private ondernemingen gebeurt. Ook het aantal samenwerkingsverbanden met andere Europese universiteiten en de hoeveelheid projectgelden uit de EU gaan er sterk op vooruit.

De effectiviteit van de inspanningen als hefboom voor de hele Luxemburgse economie zal echter afhangen van de synergieën die gecreëerd worden. Om deze te stimuleren besliste de Luxemburgse overheid in 2005 om alle verspreide vestigingen van de Uni Lu te hergroeperen op één gloednieuwe site (enkel de faculteit rechten, economie en financiën blijft in de hoofdstad). In Belval, bij Esch-sur-Alzette, verrijzen de gebouwen die de 'cité des sciences' zullen uitmaken. Op termijn moet deze uitgroeien tot een 'pôle de savoir', waar naast de universiteit ook drie onderzoekscentra onderdak krijgen, en waar 'incubatorruimte' is voor start-ups. Zo hoopt de Luxemburgse overheid met de kenniseconomie een nieuwe stevige pijler onder haar economie te zetten, naast de bank- en financiële sector, en de (al lang tanende) staalsector.

\section{Nieuwe plaats in de samenleving}

Uit deze casus blijkt hoe universiteiten naar voren worden geschoven als nieuwe groeipolen voor de (nationale) economie. In het licht van zowel economische als regulatieve bedreigingen die als een zwaard van Damocles boven de Luxemburgse economie hangen, worden er wel heel wat verwachtingen opgehangen aan de nieuw gecreëerde Uni Lu. Toen de Luxemburgse overheid besloot om te investeren in een nieuwe universiteit was dat niet enkel als bijkomende dienst voor de bevolking. Deze dienst moet worden gekaderd in een ruimere evolutie waarbij de staat, zeker op momenten dat de economie onder druk komt te staan, nieuwe pistes zoekt om te investeren. Binnen deze context krijgt de universiteit een hele nieuwe plaats in de samenleving toebedeeld. Was de Luxemburgse wereld van onderzoek en onderricht in de jaren tachtig eerder een soort vrijplaats waar individuele onderzoekers, zij het met weinig middelen, hun eigen interesses exploreerden, dan werd hij sedert eind de jaren negentig eerst uitgebouwd, en daarna geprofessionaliseerd, gestroomlijnd en ten slotte ingelijfd in het nationale ontwikkelingsbeleid.

\section{Tim Cassiers (tim.cassiers@ees.kuleuven.be) is verbonden aan de $K U$ Leuven en aan CEPS/INSTEAD in Luxemburg. Ook is hij redacteur van AGORA.}

\section{Literatuurselectie}

Henzig, L. (2010) Société du savoir et développement économique.

In: M. Hesse (Ed.), Villes universitaires. Un espace de dévelop-

pement économique et humain, pp. 39-42. Luxembourg:

Fondation Bassin Minier.

Huo, J. \& J. Stephens (2012) The Corporatist Political Economies:

From Industrial Corporatism to the Social Investment State in the Knowledge Intensive Service Economy. Working Paper 388. Kellogg institute.

Meyer, M. (2009) Creativity and its contexts: the emergence,

institutionalisation and professionalisation of science and culture in Luxembourg. European Review of History / Revue europeenne d'histoire, 16(4), pp. 453-476. 